\title{
Correction to "Clearance Prediction Methodology Needs Fundamental Improvement: Trends Common to Rat and Human Hepatocytes/Microsomes and Implications for Experimental Methodology"
}

\footnotetext{
In the above article [Wood FL, Houston JB, and Hallifax D (2017) Drug Metab Dispos 45:1178-1188; DOI: https://doi.org/10.1124/dmd.117.077040], portions of the Figure 4 legend and Figure 6 legend were incorrect, the header on page 1179 was incorrect and the citation of the Data Supplement was worded incorrectly.

In Figure 4, the "all other compounds are represented by" notation depicted with $\mathbf{\square} \mathbf{\square}$ should instead be depicted with $\diamond$.

In Figure 6, the "class 3" notation depicted with $\bullet$ should instead be depicted with $\boldsymbol{\Delta}$.

On page 1179, the header, "Data Collation Analysis" should have read "Data Collation and Analysis".

On page 1179, the citation of the Data Supplement should read: supplemental table 1 (human) and supplemental table 2 (rat).

The HTML and PDF versions of the article have been corrected.

The compositor apologizes for any inconvenience.
} 